\title{
Cesarean Section Epidemic: Coping Strategies Adopted in Brazil
}

\author{
Daniela Ferreira D’agostini Marin,* Fabiana Schuelter Trevisol, Betine Pinto MoehleckeIser \\ Postgraduate Program in Health Sciences, University of Southern Santa Catarina at Tubarão, Santa Catarina, Brazil
}

\begin{abstract}
In this article, we discuss the strategic measures adopted in Brazil to reduce the high rates of cesarean sections. We present specific programs for both public health and supplementary health and for improving maternal and child health. We hope that these governmental initiatives, coupled with a paradigm shift in the Brazilian society regarding childbirth and women's health, will reduce cesarean section rates in the short and medium run, leading to positive outcomes for maternal and children's health and well-being.
\end{abstract}

Keywords: Cesarean section, Delivery, obstetrics, Quality health care

\section{Introduction}

Childbirth in a hospital setting seeks to ensure safe healthcare services for women and newborns. The advancement of obstetrics has greatly contributed to prevent maternal and perinatal morbidity and mortality. However, it has increased the intervention rates for both women and newborns, which should otherwise be used in a weighted way and only in special situations. Excessive intervention fails to consider the emotional, human, and cultural aspects involved in the childbirth process.Childbirth care should go beyond the delivery and childbirth process. ${ }^{1}$ Childbirth should not be treated as a set of medical procedures, but as a physiological process, an important family and cultural event, and a unique moment between mother and baby. ${ }^{2}$ Providing quality healthcare during delivery and childbirth is vital to reduce maternal and neonatal morbidity and mortality. The rate of cesarean sections is an important global indicator for measuring access to obstetric care. In the last decades, cesarean section rates have increased gradually in both developed and developing countries. The determinants of such growth are controversial, but it is believed that the increase is driven largely by cesarean sections without medical indication., ${ }^{3,4}$ According to Boerma and collaborators, about 29.7 million children in 2015 (or 21.1 percent of the 140.6 million live births in the world) have been birthed by cesarean section. That corresponds to a 12 percent increase of live births in $2000 .^{5}$ Brazil is the second largest in the world in terms of cesarean section rates, accounting for 55.6 percent of all the live births. ${ }^{5,6}$ Cesarean section with medical indication and under ideal conditions is a safe procedure with low rates of serious complications. Cesarean sections can save lives, and a parturient should never be denied surgical delivery that she needs. ${ }^{5,7}$ However, when the cesarean section is not medically indicated, it poses unnecessary risks to the health of women and infants, causing immediate and long-term harm. These effects may extend for long years after delivery and may also affect future pregnancies. ${ }^{4,9,10}$

Cesarean section is associated with an increase in severe acute maternal morbidity, defined as the presence of complications, such as hemorrhage, need for hysterectomy or blood transfusion, uterine rupture, anesthetic-related complications, obstetric shock, cardiac arrest, acute renal failure, assisted ventilation or intubation, puerperal venous thromboembolism, severe puerperal infection, rupture of the operative wound, and hematomas. ${ }^{4,11}$ Long-term complications encompass pelvic adhesions, small bowel obstruction, menorrhagia, dysmenorrhea, chronic pelvic pain, and sexual dysfunction. ${ }^{7,12}$ Short-term risks for children born from cesarean section include altered immune development, allergy, atopy, asthma, and reduced diversity of the intestinal microbiota.,13 The per-

\begin{tabular}{l|l|}
\hline Quick Response Code: & *Corresponding author: Daniela Ferreira D’Agostini Marin, Av. José Acácio Moreira, 787 - \\
Dehon, Tubarão - Santa Catarina, Brazil & Published: 05 May, 2021 \\
Received: 26 March, 2021 & \\
Citation: Daniela FDMarin, Fabiana ST, Betine PM. Cesarean Section Epidemic: Coping Strate- \\
gies Adopted in Brazil. Pregn Womens Health Care Int J. 2021;1(2):1-3. D0I: \\
10.53902/PWHCIJ.2021.01.000506
\end{tabular}


sistence of these effects through adulthood is still poorly studied, although some studies highlight an association between cesarean delivery and metabolic syndrome features, including adiposity, increased blood pressure, type 1 diabetes, and increased body mass, in addition to neurological and stress-related pathologies, gastrointestinal and autoimmune diseases during childhood. However, larger-scale longitudinal studies are needed to establish causation. ${ }^{7}$

In 2011, the Oswaldo Cruz Foundation conducted a survey titled Nascer no Brasil (Be born in Brazil) that encompassed 83 percent of the births in the country. The survey identified excessive unnecessary interventions before and during delivery and postpartum, which were possibly iatrogenic illnesses, and sparked a debate among academics, professional associations, civil society, and government on the need for change. ${ }^{14}$ While the World Health Organization (WHO) suggests a cesarean delivery rate of 15 percent as a threshold, ${ }^{10}$ in Brazil the rate is as high as 55.6 percent. ${ }^{15}$ Cesarean sections account for 40 percent of the deliveries in the public health system ${ }^{16}$ and reach 84 percent in the private healthcare sector. ${ }^{17} \mathrm{~A}$ cohort study conducted in Pelotas, Rio Grande do Sul, Brazil, found a 37 percent increase in the cesarean rate between 1982 and 2015, becoming almost universal in the private sector. ${ }^{6}$ Therefore, reducing cesarean rates, especially those without medical indication, can be an important strategy in reducing maternal and neonatal morbidity and mortality, in line with the objectives of Sustainable De-

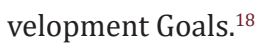

Given these alarming data, some programs have been launched to implement strategic measures to ensure high-quality prenatal care, childbirth, and postpartum care. ${ }^{2}$ In 2011, the Brazilian Unified Healthcare System (SUS in the Portuguese acronym) launched the Rede Cegonha (Stok Network) program encompassing hospitals that served public healthcare users with the objective of providing a network of care to ensure women's right to reproductive planning and humanized assistance during pregnancy, childbirth, and postpartum, as well for the child's rights of a safe birth and healthy growth and development. ${ }^{19,20}$ The Stork Network has four strategic components: I - Prenatal; II - Childbirth and birth; III - Puerperium; IV - Comprehensive attention to children's health; Logistic system; Transport and regulation..$^{21,22}$ The Stork Network is a relatively recent initiative and, for this reason, few studies are found in the literature investigating its impact. The published studies have shown that after the implementation of the Stork Network, there have been some advances, such as the encouragement of natural childbirth and increased engagement of obstetric nursing work to provide pregnant women with humanized assistance. ${ }^{21} \mathrm{~A}$ reduction in the infant mortality rate and maternal mortality was also found. ${ }^{22}$ However, some parameters need to be improved, such as providing orientation about breastfeeding, repeated tests for syphilis, HIV, and Hepatitis B, and improving the linkage between pregnant women and the reference maternity. ${ }^{21,23}$

In 2015, the Projeto Parto Adequado(Adequate Childbirth Project, developed by the National Agency for Supplementary Health, the Albert Einstein Israelite Hospital, and the Institute for Healthcare Improvement (IHI), was launched with the support of the Brazilian Ministry of Health. The objective of the project is to identi- fy innovative and viable care models during labor and childbirth, which value natural delivery and reduce the percentage of cesarean sections without indication. This initiative also aims to provide pregnant women and babies with the best healthcare, at the right time, during pregnancy, throughout labor and postpartum, which requires good facilities, well-trained multidisciplinary teams, use of evidence-based medicine, and a good socio-cultural environment for pregnant women and their families. ${ }^{24-26}$ In 2017, the Brazilian Ministry of Health launched a project for improvement and innovation in obstetric and neonatal care, called Apice-On, the aim of which is to improve clinical training and management of care during childbirth, birth, and miscarriage/abortion, using a model based on scientific evidence, humanization, safety, and patients' rights. The Apice-On project proposes healthcare improvement during pregnancy throughout labor, reproductive planning postpartum and post-abortion, assistance to women who suffer sexual violence, experience miscarriage or legal abortion, which should be provided in hospital facilities with the following characteristics: teaching hospitals, university hospitals, and/or those health units within the scope of the Stork Network. ${ }^{27}$ In the long run, it is believed that education of health professionals focused on this new healthcare model will make the difference in providing quality care for pregnant women and their infants.

In 2018, the Ministry of Health created the Projeto Parto Cuidadoso (Careful Childbirth Project), an online monitoring system to monitor the number of cesarean section deliveries in the Brazilian Unified Health System (SUS). The data are made available to the managers of the healthcare units, thus facilitating a discussion between the healthcare team and the pregnant woman about the birth plan, providing guidance to choose the most appropriate procedure for each situation, so as not to endanger the life of both the mother and the baby, and reduce unnecessary cesarean sections. ${ }^{2,28}$ The implementation of the mentioned projects requires training obstetric teams at the hospitals and public and private healthcare networks, training courses for pregnant women taught by multidisciplinary teams, protocols and standardization of prenatal care, adoption of the Robson's Classification to categorize the parturients at the obstetric admission, remodeling of the health facilities to accommodate the physiological vaginal birth, and implementation of a center for natural childbirth, providing antepartum, childbirth and postpartum rooms. Furthermore, training health professionals with such a view is recommended, thereby integrating teaching, assistance and research on innovative practices to improve healthcare for women and infants. We hope that these governmental initiatives, coupled with a paradigm shift in the Brazilian society regarding childbirth and women's health, will reduce cesarean section rates in the short and medium run, leading to positive outcomes for maternal and children's health and well-being.

\section{Acknowledgments}

None.

\section{Funding}

None. 


\section{Conflicts of Interest}

The authors declare no conflict of interest.

\section{References}

1. National guidelines for assistance in normal childbirth. Ministério da Saúde. Brasil. 2017.

2. Occhi GM, de Lamare Franco Netto T, Neri MA, et al. Strategic measures to reduce the caesarean section rate in Brazil. Lancet. 2018;392(10155):1290-1291.

3. Vogel JP, Betrán AP, Vindevoghel N, et al. Use of the Robson classifi cation to assess caesarean section trends in 21 countries: a secondary analysis of two WHO multicountry surveys. Lancet Glob Health. 2015;3(5):e260270 .

4. Cesarean Delivery on Maternal Request - ACOG. Am Coll Obstet Gynecol. 2019;133:e73-e77.

5. Boerma T, Ronsmans C, Melesse DY, etal. Global epidemiology of use of and disparities in caesarean sections. The Lancet. 2018;392(10192):13411348.

6. Barros AJD, Victora CG, Horta BL, et al. Antenatal care and caesarean sections: trends and inequalities in four population-based birth cohorts in Pelotas, Brazil,1982-2015. Int J Epidemiol. 2019;48(Supplement_1):i37145.

7. Sandall J, Tribe RM, Avery L, et al. Short-term and long-term effects of caesarean section on the health of women and children. The Lancet. Elsevier. 2018;392(10155):1349-1357.

8. Betrán AP, Temmerman $\mathrm{M}$, Kingdon $\mathrm{C}$, et al. Interventions to reduce unnecessary caesarean sections in healthy women and babies. The Lancet Elsevier. 2018;392(10155):1358-1368.

9. Agência Nacional de Saúde Suplementar Sociedade Beneficente Israelita Brasileira Hospital Albert Einstein, Institute for Healthcare Improvement. Nova organização do cuidado ao parto e nascimento para melhores resultados de saúde. Projeto Parto Adequado - Fase 1. 2006.

10. Organização Mundial de Saúde. Declaração da OMS sobre Taxas de Cesáreas. Hum Reprod Program. 2015;1-8.

11. The American College of Obstetricians and Gynecologists and the Society for Maternal-Fetal Medicine with the assistance of Aaron B. Caughey, MD, PhD; Alison G. Cahill, MD, MSCI; Jeanne-Marie Guise, MD, MPH; and Dwight J. Rouse, MD M. Safe Prevention of the Primary Cesarean Delivery. Am Coll Obstet Gynecol. 2014;(123):693-711.

12. Almeida ECS, Nogueira AA, Candido dos Reis FJ, et al. Cesarean section as a cause of chronic pelvic pain. Int J Gynecol Obstet. 2017;79(2):101-104.
13. Lewis JA. Timing of Elective Repeat Cesarean Delivery at Term and Neonatal Outcomes. MCN. Am J Matern Nurs. 2009;34(4):264.

14. Leal M do C, Pereira APE, Domingues RMSM, et al. Intervenções obstétricas durante o trabalho de parto e parto em mulheres brasileiras de risco habitual. Cad Saude Publica. 2014;30(suppl 1):S17-S32.

15. MS/SVS/DASIS - Sistema de Informações sobre Nascidos Vivos - SINASC. Nascimento por residência da mãe - Tipo de parto [Internet]. Tab Net Nascidos vivos - Brasil. 2016.

16. Brasil. Diretrizes de Atenção à Gestante: a operação Cesariana. CONITEC. 2015. p. 101.

17. Taxas Partos Cesáreos Brasil 2015 - ANS - Agência Nacional de Saúde Suplementar. 2019.

18. WHO. Uniting to accelerate progress towards the health-related SDGs towards a global action plan for healthy lives and well-being for all. 2018.

19. Despacho n.o 3482/2013. Ministério da Saúde. Diário da República, 2a série - no 45. 2013;8174-8175.

20. Ministério da saúde. Portal do Departamento de Atenção Básica [Internet]. Caderno de Atenção Básica. 2016.

21. Nascimento JS, Silva MR da, Oliveira ECT, et al. Assistência à Mulher no Pré-Natal, Parto e Nascimento: Contribuições da Rede Cegonha. Revista Portal: Saúde e Sociedade. Zeitschriften G.m.b.H. 1925;3:694-709.

22. Pacheco CG, Cavalcante D de FB, Cortellazzi KL, et al. Impacto das ações da Rede Cegonha na mortalidade materno infantil no estado de São Paulo. 2018.

23. Martinelli KG, Santos Neto ET dos, Gama SGN da, et al. Adequação do processo da assistência pré-natal segundo os critérios do Programa de Humanização do Pré-natal e Nascimento e Rede Cegonha. Rev Bras Ginecol e Obs. 2014;36(2):56-64.

24. ANS. Agência Nacional de Saúde Suplementar - Projeto Parto Adequado. 2018.

25. ANS. Agência Nacional de Saúde Suplementar Parto Adequado -Fase II. 2018.

26. Torres JA, Leal M do C, Domingues RMSM, et al. Evaluation of a quality improvement intervention for labour and birth care in Brazilian private hospitals: a protocol. Reprod Health. 2018;15(1):194.

27. Ministério de Saúde - Secretaria de Atenção à Saúde., DAPES/SAS/MS D de APECG de S das M-. Apice On Aprimoramento e Inovação no Cuidade e Ensino em Obstetrícia e Neonatologia. 2017.

28. Ministério da Saúde. Ministério da Saúde fará monitoramento online de partos cesáreos no país. Agência Saúde Ministério da Saúde. 2018. 